\title{
Spatial and Temporal Trends in Juvenile Sockeye Salmon Diets across Oceanographic Regimes on the Coast of British Columbia
}

\author{
Samantha E. James ${ }^{1,2,3}$, Evgeny A. Pakhomov ${ }^{1,2,3}$, and Brian P.V. Hunt ${ }^{1,2,3}$ \\ ${ }^{l}$ Department of Earth, Ocean and Atmospheric Sciences, University of British Columbia, 2207 Main Mall, \\ Vancouver, British Columbia, V6T 1Z4, Canada \\ ${ }^{2}$ Institute for the Oceans and Fisheries, University of British Columbia, 2202 Main Mall, Vancouver, British \\ Columbia, V6T 1Z4, Canada
}

${ }^{3}$ Hakai Institute, PO Box 309, Heriot Bay, Quadra Island, British Columbia, VOP 1HO, Canada

Keywords: sockeye salmon, diet, zooplankton, foraging success, juvenile

The Fraser River watershed is one of the world's largest sockeye salmon (Oncorhynchus nerka) producers. However, productivity in several populations has declined since the early 1990's (Peterman and Dorner 2011). It is believed that bottom-up environmental conditions and trophic interactions during the juvenile salmon early marine migration are contributing factors (Beamish and Mahnken 2001; Aydin et al. 2005; Ware and Thomson 2005; Farley and Trudel 2009). The phenology of bottom-up oceanographic processes and of the juvenile salmon outmigration are intrinsically linked (Chittenden et al. 2010; Malick et al. 2015). Indeed, the timing and size of the spring phytoplankton bloom has been demonstrated to be significantly correlated with salmon productivity (Malick et al. 2015). Furthermore, marine survival has been found to be higher when the juvenile marine outmigration overlaps with periods of high prey abundance (Chittenden et al. 2010). Long term changes to zooplankton assemblages in the Strait of Georgia have been observed (Johannessen and Macdonald 2009; Li et al. 2013), potentially impacting both the quality and quantity of prey along the juvenile salmon migratory route. Changes in the prey community may therefore explain the variability of sockeye salmon survival and returns to the Fraser River in British Columbia in recent years.

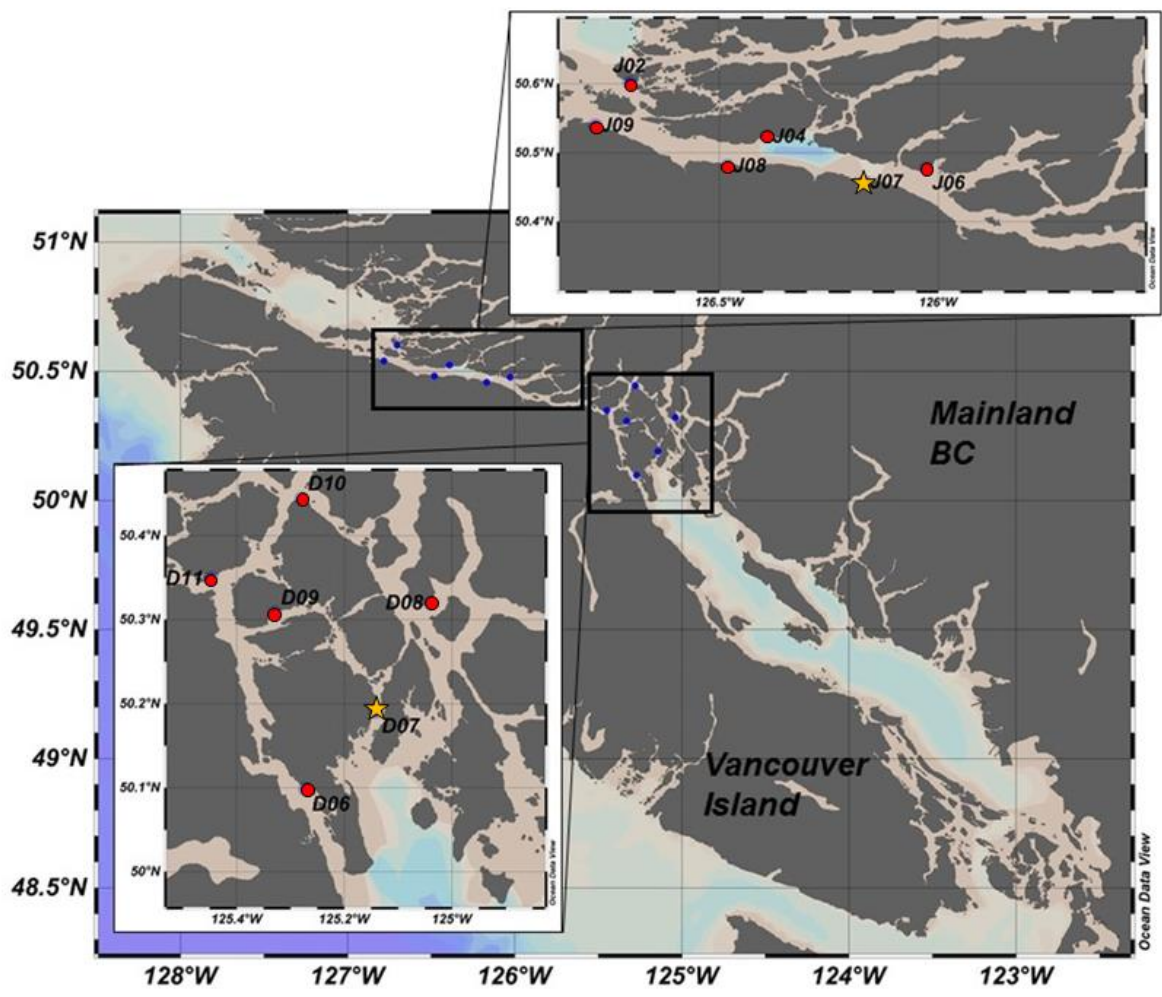

Fig. 1. Map of study area located between Vancouver Island and mainland British Columbia. Inset maps show locations of sampling sites in the Discovery Islands (bottom) and Johnstone Strait (top). All sites were used in the spatial analyses; those marked with a star were selected for temporal analyses. 
Upon leaving the Fraser River, juvenile sockeye salmon spend their first summer at sea transitioning between the different ocean regimes of the BC coastline. Juveniles first encounter the highly stratified and productive waters of the Strait of Georgia (Jackson et al. 2015) where they have been shown to reside for 43-54 days (Preikshot et al. 2012). The majority of juveniles then travel through the tidally-mixed channels of the Discovery Islands and Johnstone Strait, before continuing north through Queen Charlotte Sound and Hecate Strait en route to the Gulf of Alaska (Tucker et al. 2009) (Fig. 1). Johnstone Strait, an area with strong winds and intense tidal mixing, is a section of the migration where juvenile salmon are thought to experience an 'energy deficit,' a hypothesis known as the 'trophic gauntlet' (Mckinnell et al. 2014). This area is characterized by cooler, denser, and less productive water than in the Discovery Islands and Strait of Georgia immediately to the south. To date, very little is known about juvenile salmon diets in the Discovery Islands and Johnstone Strait. Recent research has shown that this region does support lower zooplankton biomass (Mahara 2018) and that growth is reduced relative to other sections of the outmigration (Journey et al. 2018). However, the connection between environmental conditions, prey phenology, and juvenile salmon diet and growth across fine spatial and temporal scales during the outmigration remains unexplored. This research looks to test the trophic gauntlet hypothesis and shed light on the fine scale differences in environmental conditions, prey fields, and juvenile sockeye diets across space and time.

Juvenile sockeye salmon were sampled from stations in the Discovery Islands and Johnstone Strait between May and July in 2015 and 2016 to capture the peak of the outmigration. Samples were collected using a modified purse seine deployed from an $8 \mathrm{~m}$ twin-outboard motored vessel. From each seine, 10 sockeye were taken for detailed dissections and analyses. For the purpose of the spatial analysis, samples collected between June 1 and June 9, 2015 were analyzed from six sites in each region. The sites closest to Queen Charlotte Strait and the Strait of Georgia experienced stronger influences from these regions, thus the following sub-regions were used for analyses: northwestern Johnstone Strait (J02), Johnstone Strait (J04-J09), Discovery Islands (D08-D11), and Southern Discovery Islands (D06, D07). To determine fine scale temporal changes, samples were analyzed from one site in each region (J07, D07) from late May, early June, and late June of each year. Zooplankton were sampled by conducting horizontal surface tows with a $250 \mu \mathrm{m}$ net at each sampling location after fish were captured. Environmental data were measured by taking YSI readings at the surface and at $1 \mathrm{~m}$ depths, as well as secchi readings from the location of fish capture.

Prey samples and stomach contents were analysed to the lowest taxonomic level possible and a gut fullness index (GFI) was calculated by dividing the weight of the stomach contents by the weight of the fish and converting to a percentage. For visualization of diet and zooplankton composition data, the taxonomic categories were simplified into the following major groupings: Amphipods, Barnacles, Calanoid Copepods, Cladocerans, Decapods, Euphausiids, Larvaceans, and 'Other.' The latter category consisted mainly of gastropods, bivalves, polychaetes, insects, and fish and zooplankton eggs. Detailed taxonomic information was retained for multivariate analyses. Abundance and biomass data were arcsin transformed and Bray-Curtis (BC) rank dissimilarities calculated. Differences in prey and diet composition were assessed using non-metric multidimensional scaling (NMDS) ordinations of the BC matrix. A similarity of percentages analysis (SIMPER) was used to determine which taxa contributed most to groupings of fish/zooplankton. Average GFIs from each sampling event were compared to regional values reported by Brodeur et al. (2007) to determine whether the values in this section of the coast were above or below regional averages.

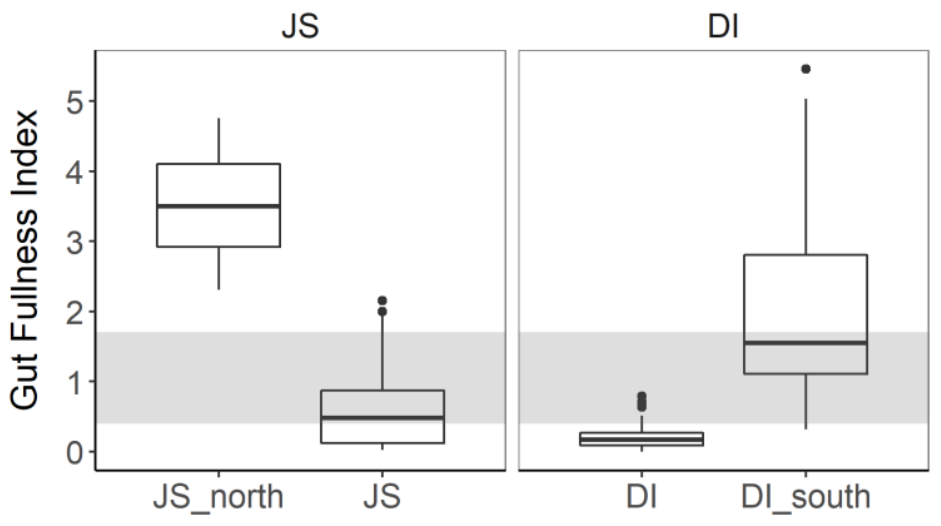

Fig. 2. Gut fullness index averaged across samples from the northwestern extent of Johnstone Strait (JS_north, $n=10$ ), Johnstone Strait (JS, $n=52$ ), the Discovery Islands (DI, $n=41$ ) and the southern extent of the Discovery Islands (DI_south, $n=18$ ) from June 2015. The grey box represents the first to third quartile of gut fullness values for juvenile sockeye collected along the northeast Pacific coast from California to Alaska in 2000-2002 (Brodeur et al. 2007). 
Spatially, GFIs were low in the Discovery Islands and Johnstone Strait in June 2015, providing support for the trophic gauntlet hypothesis (Fig. 2). However, fullness indices were higher than the regional average at the sites nearest to the stratified waters to the north and south. These areas represent 'fronts,' where the convergence of stratified and mixed waters resupplies nutrients from depth to the surface waters, increasing local productivity (Boyd 1973; Simpson and Hunter 1974; Franks 1992). The higher productivity, as well as physical dynamics along fronts, causes plankton to accumulate, attracting higher trophic levels (Polovina et al. 2001; Genin et al. 2005). The high GFIs observed in these locations indicates that biological 'hot spots' may be present at the interface between mixed and stratified waters. Given the low foraging success observed in the well-mixed waters, these types of frontal areas may in fact be important foraging grounds for juveniles to facilitate their migration through otherwise challenging conditions.

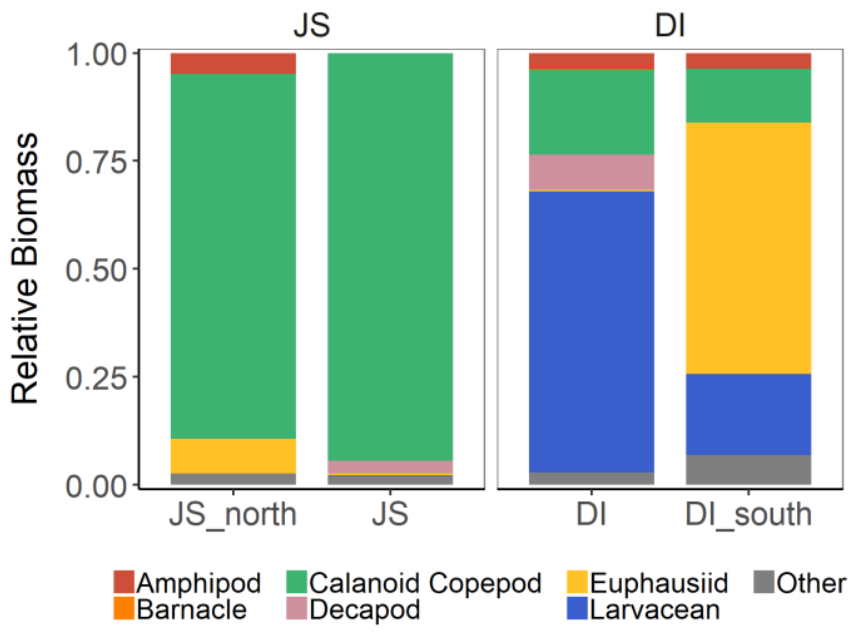

Fig. 3. Relative biomass of diet items averaged across samples from the northwestern extent of Johnstone Strait (JS_north, $n=10$ ), Johnstone Strait (JS, $n=52$ ), the Discovery Islands (DI, $n=41$ ) and the southern extent of the Discovery Islands (DI_south, $n=18$ ) from June 2015 . Only items contributing $>5 \%$ to relative biomass are included.

Analysis of the stomach contents across the four sub-regions in June 2015 revealed two unique diet types: one dominated by larvaceans and euphausiids in the warmer, fresher water of the Discovery Islands and the other dominated by large calanoid copepods in the cooler, saltier water of Johnstone Strait (Fig. 3). This differentiation agrees with recent research that identifies unique zooplankton communities across the different ocean regimes in this region (Mahara 2018). These two regions represent two separate water masses with unique prey assemblages. The Discovery Islands, despite being tidally mixed, are influenced by the warmer, seasonally stratified waters of the Strait of Georgia from the south, while Johnstone Strait receives water from the continental shelf being flushed through Queen Charlotte Strait. Thus, oceanographic conditions appear to be linked to the type and quality of prey available to migratory salmon.

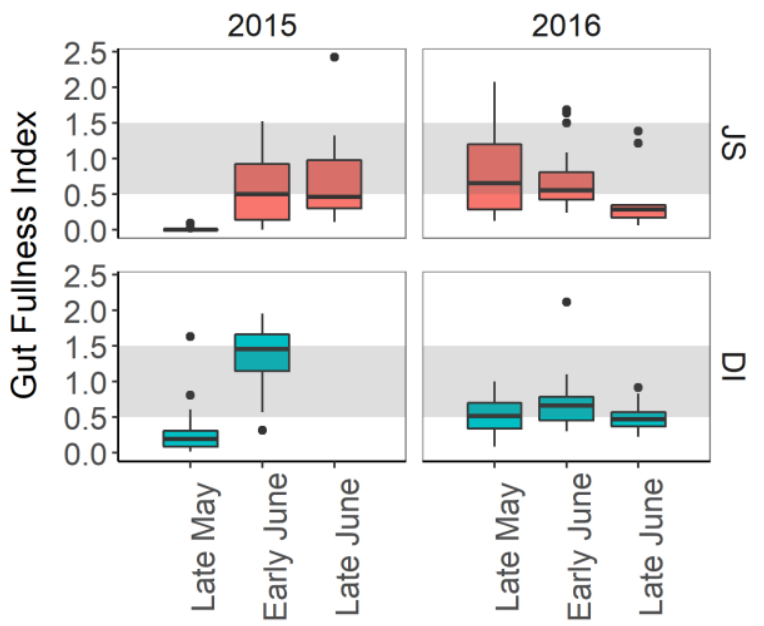

Fig. 4. Average gut fullness indices for juvenile sockeye salmon sampled in the Discovery Islands (DI) and Johnstone Strait (JS) in 2015 and 2016 across three time periods. Grey area represents the interquartile range of gut fullness values for juvenile sockeye collected along the northeast Pacific coast from California to Alaska in 2000-2002 (Brodeur et al. 2007). 
Preliminary results from the temporal analyses suggest that the GFI varies across the migratory period, rather than remaining low. In 2015, gut fullness increased during the migratory period in both regions (Fig. 4). GFIs early in the 2015 migration were low, with a higher abundance of empty stomachs in Johnstone Strait in particular. In 2016, GFIs in the Discovery Islands remained low relative to the regional average throughout the entire migratory period, while values in Johnstone Strait decreased (Fig. 4). Thus, juvenile sockeye arriving early in 2015 experienced reduced foraging success, which may have been due to a mismatch in timing with the quantity and quality of their prey. In 2015, the peak abundance of zooplankton in the surface waters occurred in mid June, one week after the peak juvenile sockeye outmigration. In contrast, peak zooplankton abundance in the surface in 2016 was observed in mid-May, two weeks prior to the peak juvenile sockeye migration.

Diets in the Discovery Islands displayed greater temporal variation both within and between seasons than those in Johnstone Strait (Fig. 5). In 2015, diets in the Discovery Islands were dominated by small zooplankton (e.g., cladocerans and barnacles) early in the season and calanoid copepods near the end of the season. In 2016, the abundance of smaller zooplankton was higher throughout the migratory period, varying between 'other' zooplankton (e.g., zooplankton eggs, echinoderm brachiolaria, gastropod veligers) and larvaceans throughout the migration. In contrast, Johnstone Strait was dominated by calanoid copepods throughout the migratory season in both years, with higher abundances of larvaceans and decapods early in the 2015 migratory period. Therefore, a higher abundance of smaller zooplankton in 2016 may have contributed to the lower GFIs observed.

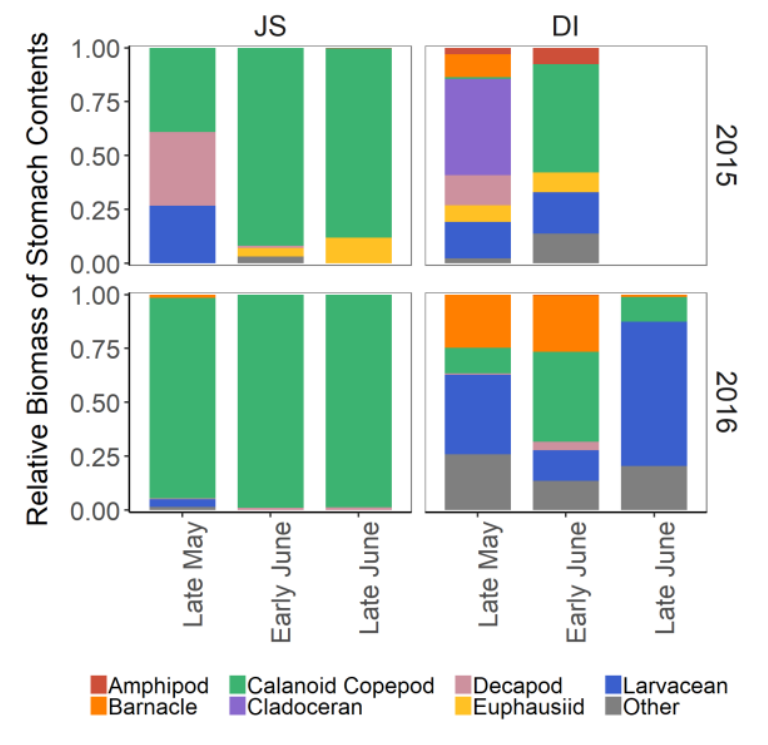

Fig. 5. Relative abundance of prey items averaged across fish sampled in each time period in the Discovery Islands (DI) and Johnstone Strait (JS) in 2015 and 2016. Only items contributing > $5 \%$ to relative abundance are included. No sampling was conducted in the Discovery Islands in Late June 2015.

In summary, juvenile sockeye can experience low foraging success in the tidally mixed Discovery Islands and Johnstone Strait, which may limit growth and affect their survival in years when they experience poor feeding conditions north or south of the mixed zone. However, we identified foraging hotspots at the southern and northernmost sites, where the mixed zones interfaced with stratified waters. These interface zones may provide essential energy to juveniles during their outmigration. While overall GFIs were lower than the regional average, they were variable over time, suggesting that conditions experienced by juvenile salmon can be favourable depending on the timing of their migration. Furthermore, prey and diets were composed of significantly different taxa between two neighbouring regions within a $150 \mathrm{~km}$ stretch of the salmon migratory route. Diets in the Discovery Islands were dominated by smaller meroplankton and larvaceans and exhibited seasonal succession, and those from Johnstone Strait were dominated by calanoid copepods throughout the entire migratory period in both years. This research demonstrates how bottom-up factors can influence the foraging success of juvenile salmon across fine spatial and temporal scales and provides new insight into foraging dynamics in mixed coastal waters.

\section{REFERENCES}

Aydin, K.Y., G.A. Mcfarlane, J.R. King, B.A. Megrey, and K.W. Myers. 2005. Linking oceanic food webs to coastal production and growth rates of Pacific salmon (Oncorhynchus spp.), using models on three scales. Deep-Sea Res. PT II. 52 (5-6): 757-780.

Beamish, R.J., and C. Mahnken. 2001. A critical size and period hypothesis to explain natural regulation of salmon abundance and the linkage to climate and climate change. Prog. Oceanogr. 49: 423-437. 
Boyd, C.M. 1973. Small scale spatial patterns of marine zooplankton examined by an electronic in situ zooplankton detecting device. Netherlands. J. Sea Res. 7: 103-111.

Brodeur, R.D., E.A. Daly, M.V. Sturdevant, T.W. Miller, J.H. Moss, M.E. Thiess, M. Trudel, L.A. Weitkamp, J. Armstrong, and E.C. Norton. 2007. Regional comparisons of juvenile salmon feeding in coastal marine waters off the west coast of North America. Am. Fish. Soc. Symp. 57: 183-203.

Chittenden, C.M., J.L. Jensen,, D. Ewart, S. Anderson, S. Balfry, E. Downey, A. Eaves, S. Saksida, B. Smith, S. Vincent, D. Welch, and R.S. McKinley. 2010. Recent salmon declines: a result of lost feeding opportunities due to bad timing? PLoS One 5: 10.

Farley, E.V., and M. Trudel. 2009. Growth rate potential of juvenile sockeye salmon in warmer and cooler years on the Eastern Bering Sea Shelf. J. Mar. Biol. 2009: 1-10.

Franks, P.J.S. 1992. Sink or swim: accumulation of biomass at fronts. Mar. Ecol. Prog. Ser. 82: 1-12.

Genin, A., J.S. Jaffe, R. Reef, C. Richter, and P.K.S. Franks. 2005. Swimming against the flow: a mechanism of zooplankton aggregation. Science. 308: 860-862.

Jackson, J.M., R.E. Thomson, L.N. Brown, P.G. Willis, and G.A. Borstad. 2015. Satellite chlorophyll off the British Columbia Coast, 1997-2010. J. Geophys. Res. Ocean. 120: 4709-4728.

Johannessen, S.C., and R.W. Macdonald. 2009. Effects of local and global change on an inland sea: the Strait of Georgia, British Columbia, Canada. Clim. Res. 40: 1-21.

Journey, M.L., M. Trudel, G. Young, and B.R. Beckman. 2018. Evidence for depressed growth of juvenile Pacific salmon (Oncorhynchus) in Johnstone and Queen Charlotte Straits, British Columbia. Fish. Oceanogr. 27: 174-183.

Li, L., D. Mackas, B. Hunt, J. Schweigert, E. Pakhomov, R.I. Perry, M. Galbraith, and T.J. Pitcher. 2013. Zooplankton communities in the strait of Georgia, British Columbia, track large-scale climate forcing over the pacific ocean. Prog. Oceanogr. 115: 90-102.

Mahara, N. 2018. Zooplankton Community Composition Across a Range of Productivity Regimes in Coastal British Columbia. M.Sc. thesis, Univ. British Columbia, Vancouver. 108 pp.

Malick, M.J., S.P. Cox, F.J. Mueter, and T.M. Peterman. 2015. Linking phytoplankton phenology to salmon productivity along a north - south gradient in the Northeast Pacific Ocean. Can. J. Fish. Aquat. Sci. 72(5): 697-708.

Mckinnell, S., E. Curchitser, K. Groot, M. Kaeriyama, and M. Trudel. 2014. Oceanic and atmospheric extremes motivate a new hypothesis for variable marine survival of Fraser River sockeye salmon. Fish. Oceanogr. 23: $322-341$.

Peterman, R.M., and B. Dorner. 2011. Fraser River sockeye production dynamics. Cohen Commission Technical Report 10: 133 pp. Vancouver, BC.

Polovina, J.J., E. Howell, D.R. Kobayashi, and M.P. Seki. 2001. The transition zone chlorophyll front, a dynamic global feature defining migration and forage habitat for marine resources. Prog. Oceanogr. 49: 469-483.

Preikshot, D., R.J. Beamish, R.M. Sweeting, C.M. Neville, and T.D. Beacham. 2012. The residence time of juvenile Fraser River sockeye salmon in the Strait of Georgia. Mar. Coast. Fish. 4: 438-449.

Simpson, J.H., and J.R. Hunter. 1974. Fronts in the Irish Sea. Nature. 250: 404-406.

Tucker, S., M. Trudel, D.W. Welch, J.R. Candy, J.F.T. Morris, M.E. Thiess, C. Wallace, D.J. Teel, W. Crawford, E.V. Farley, and T.D. Beacham. 2009. Seasonal stock-specific migrations of juvenile sockeye salmon along the west coast of North America: implications for growth. Trans. Am. Fish. Soc. 138: 1458-1480.

Ware, D.M., and R.E. Thomson. 2005. Bottom-up ecosystem trophic dynamics determine fish production in the Northeast Pacific. Science. 308: 1280-1283. 